1,2 Lim* $^{*}{ }^{3} \mathrm{~L}$ March, ${ }^{3} \mathrm{M}$ Barbour, ${ }^{1,2} \mathrm{H}$ Haughn, ${ }^{1,2} \mathrm{~S}$ Levy, ${ }^{1,2} \mathrm{~K}$ Prijoles, ${ }^{1,2} \mathrm{D}$ Bass,

${ }^{1,2} \mathrm{G}$ Barros, ${ }^{1,2} \mathrm{C}$ Kelly, ${ }^{3} \mathrm{~F}$ Chassagne, ${ }^{1,3} \mathrm{~A}$ Aliseda, ${ }^{1,2} \mathrm{M}$ Levitt, ${ }^{1,2} \mathrm{~L} \mathrm{Kim} .{ }^{1}$ Neurological Surgery, University of Washington, Seattle, WA; ${ }^{2}$ Stroke and Applied Neuroscience Center,

University of Washington, Seattle, WA; ${ }^{3}$ Mechanical Engineering, University of Washington, Seattle, WA

\subsection{6/neurintsurg-2020-SNIS.251}

Introduction Despite advancements in endovascular treatment of intracranial aneurysms, up to $30 \%$ recur and require
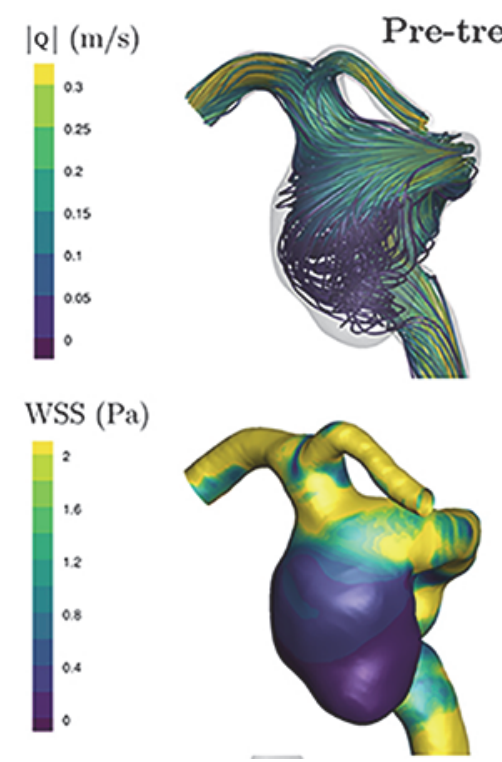
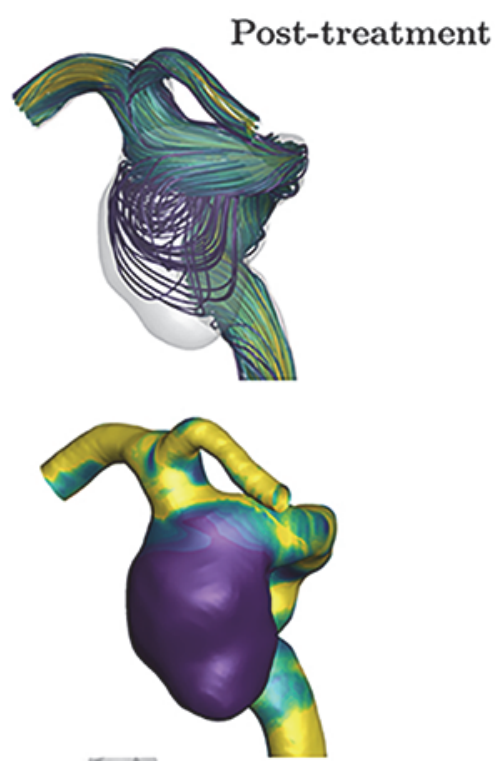

Abstract E-220 Figure 1 Patient-specific computational fluid dynamics modelling (CFD) of changes in flow (Q) (top) and wall shear stress (WSS) (bottom) in an intracranial aneurysm before (left) and after (right) treatment by flow-diverting stent

\begin{tabular}{|c|c|c|c|c|c|c|c|}
\hline $\mathrm{N}$ & Age & Sex & Smoking Status & History of Hypertension & Aneurysm Location & $\begin{array}{l}\text { Largest Aneurysm } \\
\text { Dimension }(\mathrm{mm})\end{array}$ & Pipeline Size (mm) \\
\hline 1 & 64 & $\mathrm{~F}$ & $\mathrm{~N}$ & Y & L ICA supraclinoid & 11.0 & $4 \times 20$ \\
\hline 2 & 77 & $\mathrm{~F}$ & $\mathrm{~N}$ & Y & L ICA paraclinoid & 10.0 & $4 \times 16$ \\
\hline 3 & 46 & $\mathrm{~F}$ & N & $\mathrm{N}$ & L ICA cave & 5.0 & $4.25 \times 16$ \\
\hline 4 & 32 & $\mathrm{~F}$ & Y & Y & L ICA ophthalmic & 10.0 & $4 \times 20^{*}$ \\
\hline 5 & 50 & $\mathrm{~F}$ & N & $\mathrm{N}$ & R ICA cavernous and ophthalmic & 10.0 & $4.75 \times 18$ \\
\hline 6 & 65 & M & $\mathrm{N}$ & Y & L ICA paraclinoid/para-ophthalmic & 7.0 & $4.75 \times 18$ \\
\hline 7 & 38 & $\mathrm{~F}$ & N & $\mathrm{N}$ & L ICA cavernous & 30.0 & $3.75 \times 30$ \\
\hline 8 & 40 & $\mathrm{~F}$ & N & $\mathrm{N}$ & L ICA ophthalmic and superior hypophyseal & 6.0 & $3.75 \times 16$ \\
\hline 9 & 68 & $\mathrm{~F}$ & Y & Y & R ICA ophthalmic & 8.0 & $5 \times 18$ \\
\hline 10 & 66 & $\mathrm{~F}$ & $\mathrm{~N}$ & $\mathrm{~N}$ & L ICA ophthalmic & 6.5 & $4.75 \times 16$ \\
\hline 11 & 72 & $\mathrm{~F}$ & N & $\mathrm{N}$ & L ICA supraclinoid & 13.0 & $5 \times 18$ \\
\hline 12 & 76 & $\mathrm{~F}$ & $\mathrm{~N}$ & Y & L ICA PCOM & 21.6 & $5 \times 16$ \\
\hline 13 & 47 & $\mathrm{~F}$ & Y & Y & L ICA ophthalmic & 14.0 & $3.5 \times 16$ \\
\hline 14 & 47 & M & $\mathrm{N}$ & Y & L ICA ophthalmic & 6.0 & $4.5 \times 20$ \\
\hline 15 & 39 & M & $\mathrm{N}$ & $\mathrm{N}$ & L ICA ophthalmic, L ICA cavernous & $5.0,4.0$ & $5 \times 20$ \\
\hline 16 & 47 & $\mathrm{~F}$ & Y & $\mathrm{N}$ & R IRCA supraclinoid & 5.0 & $4.5 \times 16$ \\
\hline 17 & 62 & $\mathrm{~F}$ & $\mathrm{~N}$ & $\mathrm{~N}$ & R ICA PCOM & 12.0 & $4 \times 16$ \\
\hline 18 & 51 & $\mathrm{~F}$ & Y & $\mathrm{N}$ & L ICA supraclinoid & 29.0 & $4.5 \times 16^{* *}$ \\
\hline 19 & 80 & $\mathrm{~F}$ & $\mathrm{~N}$ & Y & L ICA Suparclinoid and cavernous & 35.0 & $5 \times 30$ \\
\hline 20 & 60 & $\mathrm{~F}$ & $\mathrm{~N}$ & $\mathrm{Y}$ & R ICA cavernous & 10.6 & $5 \times 18$ \\
\hline 21 & 53 & $\mathrm{~F}$ & $\mathrm{~N}$ & $\mathrm{~N}$ & R ICA cavernous & 6.5 & $4.75 \times 18$ \\
\hline 22 & 33 & $\mathrm{~F}$ & N & Y & L ICA cavernous & 10.5 & $5 \times 25$ \\
\hline 23 & 57 & $\mathrm{~F}$ & $\mathrm{~N}$ & $\mathrm{~N}$ & R ICA ophthalmic & 7.0 & $4.5 \times 16$ \\
\hline 24 & 57 & $\mathrm{~F}$ & Y & $\mathrm{N}$ & R ICA supraclinoid & 9.6 & $4.75 \times 16$ \\
\hline
\end{tabular}


additional treatment. Predicting outcomes after aneurysm treatment with flow-diverting stents (FDS) could impact treatment strategy and avoid unnecessary follow-up. Computational fluid dynamics (CFD) techniques have been used to simulate the effect of treatment on the intracranial aneurysm hemodynamics, and to quantify change in certain hemodynamics factors that can be associated with treatment success or failure. We use CFD simulations, based on aneurysm anatomy and patient-specific blood flow and pressure data, to study which hemodynamics factors are predictive of six-month treatment outcomes.

Materials and Methods Twenty-four patients with $n=25$ unruptured intracranial aneurysms treated with FDS were included (Table 1). 3-dimensional rotational angiographic anatomy was used to create the computational model and intraoperative blood velocity and blood pressure measurements proximal to the aneurysm, obtained with an endovascular dual-sensor microwire, were used as boundary conditions for CFD simulations before and after FDS treatment. For post-treatment calculations, a virtual stent based on the Pipeline Flex Embolization Device was deployed into the CFD simulations. Hemodynamics factors within the aneurysm dome including flow into aneurysm (Q), wall shear stress (WSS), wall shear stress gradient (WSSG), viscous dissipation, oscillatory shear index (OSI), and relative residence time (RRT) were calculated before and after FDS placement. Aneurysm treatment was classified as success or failure based on six-month follow-up angiography. Hemodynamics changes between immediate posttreatment and pre-treatment simulations were associated to treatment outcomes.

Results Marked reduction in Q, WSS, WSSG, and OSI were seen in most cases immediately after FDS treatment compared to the pretreatment values, indicative of the redirection of blood flow along the neck plane. Reduction of $\mathrm{Q}$ at peak systole and increase in RRT in the aneurysm dome were strong predictors of FDS treatment success. Further multivariate analysis of hemodynamic predictors of treatment outcome will be presented.

Conclusion Patient-specific CFD simulations using intraoperative physiological velocity and pressure data have been performed pre- and immediately post-treatment. Hemodynamics factors have the potential to predict aneurysm treatment outcomes, making them valuable for neurointerventionalists to consider in treatment planning.

Disclosures D. Lim: None. L. March: None. M. Barbour: None. H. Haughn: None. S. Levy: None. K. Prijoles: None. D. Bass: None. G. Barros: None. C. Kelly: None. F. Chassagne: None. A. Aliseda: None. M. Levitt: 1; C; Philips Volcano. L. Kim: None.

\section{E-221 TRANSULNAR ARTERIAL ACCESS FOR DIAGNOSTIC CEREBRAL ANGIOGRAPHY AND NEUROVASCULAR INTERVENTION}

${ }^{1} \mathrm{R}$ Mattay*, ${ }^{1} \mathrm{M}$ Cox, ${ }^{1} \mathrm{P}$ Ramchand, ${ }^{1} \mathrm{~N}$ Sedora-Roman, ${ }^{1} \mathrm{~B}$ Pukenas, ${ }^{2} \mathrm{D}$ Kung, ${ }^{1} \mathrm{R}$ Hurst, ${ }^{2} O$ Choudhri. ${ }^{1}$ Radiology, Hospital of the University of Pennsylvania, Philadelphia, PA; ${ }^{2}$ Neurosurgery, Hospital of the University of Pennsylvania, Philadelphia, PA

10.1136/neurintsurg-2020-SNIS.252
Purpose Supported by longstanding Class I evidence from the cardiology literature showing the safety of transradial artery access for coronary angiography (Choe et al., 2016), an increasing number of neurointerventionalists have adopted the transradial approach for diagnostic cerebral angiography (Almallouhi et al., 2020). A recent study specifically showed the noninferiority of transradial arterial access compared with the transfemoral approach for cerebral angiography (Stone et al., 2020). As the transradial approach becomes more widely adopted, a few important caveats have become apparent that may preclude safe transradial arterial access (namely variant anatomy, vasospasm, or radial artery occlusion). In such cases, a transfemoral or transulnar approach may be the most feasible route for arterial access. The purpose of study was to document the feasibility and safety of ulnar artery access for both diagnostic cerebral angiography and neurointerventional cases.

Materials and Methods A retrospective review of a local institutional database at a high-volume neurovascular center was performed. Consecutive diagnostic and interventional neurovascular cases completed solely via ulnar artery access over a 12 month period were reviewed and analyzed. Data including type of case (diagnostic or interventional), reason for choosing ulnar artery access, technical success for ulnar artery cannulation, successful case completion, and complications were recorded.

Results The ulnar artery was accessed for 12 distinct cases in 11 patients over a 12 -month period. The mean age was 52.5 years \pm 16 years, and 8 total were female. Of these 12 procedures, 8 were diagnostic cerebral angiograms and 4 were neurovascular interventions. The intervention cases included pipeline flow diversion of an unruptured paraclinoid aneurysm, Pulserider stenting and coiling of an unruptured basilar tip aneurysm, coil embolization of a ruptured posterior communicating artery, and pre-operative embolization of a left cerebellopontine angle tumor. All 8 diagnostic angiograms were performed using $5 \mathrm{Fr}$ sheaths and all 4 interventions required 6 Fr sheaths. The right ulnar artery was accessed in 9 out of 12 cases $(75 \%)$. In all 12 cases, the ulnar artery was chosen for cannulation after ultrasound examination of the ipsilateral radial artery proved unfavorable for the procedure in question. The reasons for choosing the ulnar artery over the ipsilateral radial artery were the following: radial artery spasm (1 case), inability to pass the wire (1 case), and the remainder due to a dominant ulnar artery (ulnar artery diameter $>$ ipsilateral radial artery diameter). All procedures were successfully completed without a need for conversion to femoral arterial access. All sites of ulnar artery access were closed via an inflatable band closure device. There were no forearm hematomas, hand ischemia, or arm nerve damage in any of the 12 cases.

Conclusion Transradial arterial access has been shown to have a lower rate of access site complications when compared with the femoral approach. Our experience suggests that transulnar artery access may also be a feasible and safe alternative for diagnostic cerebral angiography and neurovascular intervention.

Disclosures R. Mattay: None. M. Cox: None. P. Ramchand: None. N. Sedora-Roman: None. B. Pukenas: None. D. Kung: None. R. Hurst: None. O. Choudhri: None. 